\title{
ESTUDANTES COM DESVANTAGENS ECONÔMICAS E EDUCACIONAIS E FRUIÇÃO DA UNIVERSIDADE
}

\author{
Wilson Mesquita de Almeida*
}

\section{INTRODUÇÃO}

O presente artigo discute a utilização dos recursos e espaços de uma conceituada universidade por estudantes com desvantagens econômicas e educacionais. ${ }^{1}$ A problemática centrou-se na dinâmica da permanência vivida por um grupo de alunos com perfil distinto daquele tido como típico da USP.

Em primeiro lugar, faço uma breve revisão crítica da bibliografia sobre a trajetória de estudantes das camadas populares que chegam ao ensino superior, a partir do diálogo com pesquisadores nacionais e estrangeiros. Em seguida, discuto alguns resultados da investigação, esperando contribuir para a reflexão sobre os debates atuais em torno da inclusão social no ensino superior brasileiro.

* Professor do Centro Universitário Nove de Julho (UNINOVE) e Mestre pela Universidade de São Paulo. Av. Prof. Luciano Gualberto, 315. Cep: 05508-010 - Sao Paulo, SP - Brasil. Telefone: (011) 30913724. wilmesq@gmail.com

${ }^{1}$ Este artigo traz alguns resultados da minha pesquisa de mestrado no Departamento de Sociologia da USP. Para a realização do trabalho, obtive auxílio da Fundação de Amparo à Pesquisa do Estado de São Paulo (Fapesp).

\section{SEGMENTOS POPULARES E EDUCAÇÃO SUPERIOR}

Atualmente, ainda que por razões diferentes em cada país, há uma maior atenção sobre a trajetória, até o ensino superior, de indivíduos pertencentes a segmentos social e economicamente desprovidos. Na França, desde a pesquisa seminal de Bourdieu e Passeron (1964), alguns estudiosos pesquisam a mudança ocorrida em um período de trinta e cinco anos e procuram compreender a transição do "estudante herdeiro" para o "novo estudante" proposto por Erlich (1998, 2004). O interesse volta-se para a compreensão das conseqüências do grande crescimento de um novo tipo de estudante, mais diverso e multifacetado em relação aos "herdeiros", que mantinham certas características típicas marcadas pelo cultivo da erudiçãoliteratura clássica, teatro, pintura, dentre outros-, retratadas em Bourdieu (1988). Nesse sentido, houve um deslocamento do olhar para a vida cotidiana dos estudantes -jornadas estudantis, modo de vida, relação com o trabalho universitário, maneiras de estudar, financiamento da vida estudantil com alo- 
jamentos, alimentação, saúde, enfim, uma série de atividades que levam alguns, às vezes de forma exagerada, a defender uma "sociologia dos estudantes" dentro do quadro das relações entre educação e sociedade (Bonnet; Clerc, 2001).

Os estudos dos países de língua inglesa estão mais centrados no acesso de estudantes - e aqui, guardadas as diferenças, há uma possível aproximação com o contexto brasileiro ${ }^{2}-$, já que existe direção explícita do governo de ampliar a participação em pelo menos $50 \%$ dos jovens que estão na faixa de dezoito a trinta anos até o ano de 2010, com a recomendação básica de que tais jovens "necessitam ser recrutados de grupos desfavorecidos, pois a participação entre jovens oriundos de grupos da classe trabalhadora tem permanecido persistentemente baixa." (Ross et al., 2003, p. 3).

No Brasil, faz alguns anos, movimentos sociais, intelectuais, pesquisadores e gestores de políticas públicas têm feito considerações sobre o acesso restrito das camadas menos favorecidas da população ao ensino superior. Associado a tais discussões, encontramos o debate atual sobre políticas de ações afirmativas como cotas raciais e cotas sociais, o qual tem dividido a opinião no país em pólos bem delimitados. Nesse quadro, pesquisas têm sido realizadas com o objetivo de melhor entender a luta por acesso à universidade, sobretudo as públicas, voltadas para esses segmentos. ${ }^{3}$

A partir das pistas teóricas abertas por Lahire (1997), estudos foram realizados procurando compreender o processo de chegada ao ensino superior das camadas sociais desfavorecidas. Assim, Viana (2000) verificou os modelos socializadores existentes nessas famílias. Como resultado, ao contrário do "superinvestimento familiar" das camadas médias, não havia, entre os entrevistados, es-

${ }^{2}$ Em terras brasileiras, há uma proposta de aumento na faixa dos jovens de 18 a 24 anos - faixa considerada ideal para a matrícula no ensino superior - para cerca de $30 \%$ até o ano de 2010, conforme consta no Plano Naciona de Educação. Atualmente, essa taxa encontra-se em torno de 8 a $9 \%$.

${ }^{3}$ Há uma variedade de denominações para dar conta desses grupos: camadas populares, jovens pobres, setores de baixa renda, jovens trabalhadores, dentre outras. tratégias previamente definidas. Portes (2000) encontrou, como traços marcantes que ajudaram no acesso, a presença de uma ordem moral doméstica, a atenção para com o trabalho escolar dos filhos e a presença de professores responsáveis por orientá-los com as melhores opções para a garantia de uma trajetória segura de escolaridade.

Alguns dos estudos realizados, tanto no Brasil quanto nos contextos francês e inglês, procuravam chamar atenção para a permanência de estudantes oriundos das camadas populares no ensino superior, ultrapassando o sentido usual de propiciar condições mínimas para o não abandono do curso. O que esses estudos propõem é uma reflexão sobre o quê, efetivamente, esse estudante socialmente desfavorecido extrai de sua passagem pela universidade. Cumpre destacar o estudo desenvolvido por Villas Bôas (2001), em que a autora problematiza as desigualdades sociais na universidade. Além das dificuldades de acesso - restrições ao ingresso, hierarquia interna de carreiras - há a emergência de distintas vivências e aproveitamento do curso de acordo com as classes sociais às quais os indivíduos pertencem.

A pesquisa efetuada procurou deslocar o foco para a investigação de processos desiguais, no nível de cada carreira, vivenciados pelos diversos indivíduos que nelas ingressam. Essas diferenciações são produzidas mediante o envolvimento com pesquisas, a apropriação de equipamentos materiais, a realização de cursos extracurriculares, além de informações sobre programas de cunho formativo existentes no âmbito da universidade. Procura-se integrar à análise do acesso àquilo que poderia ser denominado, provisoriamente, de permanência efetiva, pois, além da dimensão material apontada em vários estudos, incorpora discussões que perpassam fortemente o trajeto do estudante: o que traz consigo em termos de formação cultural valorizada pelo ambiente universitário de que passa a fazer parte; a confrontação com métodos de ensino diferenciados, onde podem ocorrer tensões, o aumento das tarefas escolares que exigem uma postura mais independente; os constrangimentos emocionais ao marcar uma 
entrada em um universo distinto, tecido por intensas mudanças - um novo espaço que rompe com relacionamentos mais sólidos até então existentes em níveis escolares anteriores, uma sociabilidade mais fragmentada com os colegas. Em suma, procura-se percorrer as rupturas e rearranjos que ocorrem quando da entrada e vivência na universidade, o que requer a reestruturação de alguns referenciais na vida estudantil.

\section{ESTUDANTES COM DESVANTAGENS SOCIAIS ${ }^{4}$}

Dezessete indivíduos dos cursos de Geografia, Letras, História, Ciências Contábeis e Física foram pesquisados. A presença masculina comparece com onze alunos, seguida de seis mulheres. A cor ${ }^{5}$ branca é predominante, perfazendo dez pessoas, seguida de parda com quatro, negra com duas e, por fim, um indivíduo que se declarou índio. Catorze pessoas estão solteiras, duas estão casadas, sendo que um dos estudantes é casado e possui uma filha de três anos. Todos estudaram em escolas públicas.

A grande maioria é composta de filhos de migrantes vindos de estados do Nordeste e do interior de São Paulo. Somente dois informantes possuem pais nascidos na cidade de São Paulo. Destaca-se a situação particular de Robson, Carolina e Adauto: eles nasceram, respectivamente, no Paraná e em Minas Gerais. É lícito supor que não se trata de algo fortuito, uma mera coincidência. Gomes (1992, p. 100) em seus estudos sobre a socialização no âmbito familiar dos grupos populares, já encontrara que “... pais migrantes educam os filhos, no meio urbano-industrial, em condições assaz desvantajosas (...) educam os filhos para uma realidade que lhes é, ainda, desconhecida (...) eles ainda estão em processo de adaptação e ajustamento ao novo meio (...) a metrópole que mal conhecem”. Embora já residentes há algum tempo

${ }^{4}$ Os nomes dos entrevistados são fictícios, para garantir o anonimato.

${ }^{5}$ Informação obtida mediante autodeclaração. O IBGE considera pretos e pardos de forma agregada, classificando-os como negros. Mantive as denominações nativas. em São Paulo, é preciso ressaltar que alguns desses pais foram fortemente socializados no ambiente rural.

Ao analisar a trajetória ocupacional paterna, depreende-se que seus pais possuem modestos recursos econômicos e exercem profissões de status relativamente baixo. Porém ocupam ou ocuparam cargos que garantiram uma certa regularidade salarial, em categorias tais como metalúrgicos, motoristas, serralheiro e mecânico de autos. A trajetória ocupacional da mãe apresenta um quadro mais precário em termos de valorização social das profissões, sendo que o trabalho informal, sem registro, foi a tônica: das que trabalharam fora, a profissão de doméstica foi predominante, seguida de costureira, lavadeira e cozinheira.

Quanto à escolaridade, há uma predominância de baixa escolarização, tanto materna quanto paterna. Um capital escolar elevado dos pais, embora seja um dos principais trunfos utilizados no espaço educacional, por si só não é sinônimo de escolarização bem sucedida dos filhos. Assim, é preciso tentar compreender como esses pais lidavam com a educação dos filhos, que importância davam às tarefas escolares, se ajudavam ou não, e que meios mobilizavam. A baixa escolaridade dos pais não lhes permitia dar auxílio nos deveres da escola. Como diz Clara "... não tinham instrução para esse tipo de coisa”. A despeito disso, um elemento que marca o olhar interessado - na maioria das vezes da mãe - foi a "cobrança" de ir bem na escola, ter resultados. Embora restrita a ver os boletins, ir às reuniões quando convocados, a maior parte dos pais demonstrava com essas atitudes suas preocupações. Logo, um elemento que atravessa todos os dezessete informantes é um ambiente familiar favorável, marcado pelo desejo de que os filhos atingissem os vários níveis de escolaridade, porém, feito de forma dialogada, nunca em termos de imposição ou pressão. Assim, houve, para todos eles, uma estabilidade emocional. Ou seja, na ausência de um capital cultural no sentido que Bourdieu (1999) propõe, sobretudo aquele transmitido na fase de socialização primária, o mais decisivo deles - capital cultural incorporado-, esses 
pais procuravam manifestar em suas relações com os filhos uma conduta de valorização da escola. A mãe de Mauro evidencia essa postura ativa “... ela trabalhava em casa de família e ganhava muitos livros escolares. Lembro que tinha muita dificuldade nos primeiros anos em ditado. Ela pegava os livros e me fazia treinar escrita."

Os irmãos tiveram presença marcante ao servirem de modelos para alguns dos pesquisados. Assim, quem formou culturalmente Gilberto marcado pela ausência paterna desde cedo - foi um irmão que trabalhava como gerente de um restaurante e “... tinha o hábito de trazer jornais para casa. Foi quando aprendi a ler histórias em quadrinhos, esse meu irmão colecionava, e também fazer palavras cruzadas”. Otávio sempre se espelhou na trajetória da irmã, que também fez contabilidade na USP. Mauro também aponta seu irmão como referência fundamental: “... meu irmão mais velho estudou no Serviço Nacional da Indústria - SENAI e ele sempre me incentivou a estudar. Num tempo em que ter um curso profissionalizante era um fator de sucesso, isso me atraía para o estudo."

A trajetória no ensino fundamental também possibilita um olhar mais apurado sobre algumas clivagens entre os pesquisados. Alguns tiveram destaque no ensino fundamental, sendo vistos como alunos-modelo: Antônio, Gilberto, Mauro e Otávio. Os professores incentivavam Gilberto a prosseguir os estudos, pois o achavam bom aluno. Antônio recebeu um prêmio entre os alunos do município de Francisco Morato, ${ }^{6}$ após ter tirado o conceito máximo durante todo o primeiro bimestre da $6^{a}$ série. Otávio era o "exemplo da escola”, aquele que tirava as maiores notas. Mauro resume bem esse subgrupo “... a lembrança mais marcante é que me consideravam um gênio na escola. Era uma coisa absurda: todos os professores me conheciam, falavam de mim até em horários em que eu não estudava."

Todos os pesquisados, sem exceção, são trabalhadores, a maioria em tempo integral, inclusi-

${ }^{6}$ Município da Grande São Paulo. Possui os índices sociais mais precários do estado de São Paulo. ve aos sábados e alguns domingos e feriados, como é o caso de Carolina. Alguns trabalham desde muito cedo $^{7}$ para seu sustento e ajuda no orçamento familiar. ${ }^{8}$ Em alguns casos, já constituíram suas próprias famílias ou são responsáveis pelo orçamento da casa. Aproximam-se da definição feita por Hirano et al. (1987, p. 84):

... uma parte do alunado da USP apresentaria uma condição institucional diferenciada, anterior à condição de estudante: é estudante sendo, antes de tudo, um trabalhador. Nesta situação, ele pode ser responsável ou não pelo orçamento familiar. Neste caso, ele pode ser pai ou apenas um membro dessa unidade familiar. [grifos meus]

Logo, os alunos pesquisados podem ser denominados trabalhadores-estudantes, possuindo uma dupla condição, ao combinar jornada longa de trabalho e estudo à noite, diferenciando-se, assim, de outros grupos de estudantes da USP: tanto em relação ao estudante dos anos sessenta, que mantinha uma forte dependência econômica da família, segundo a pesquisa de Foracchi (1965, 1982), quanto de alguns grupos que somente se dedicam aos estudos ou, mais decisivo para a situação em tela, estão livres da necessidade inadiável de trabalhar para sobreviver.

Um outro aspecto explorado no decorrer da investigação foi a "escolha" da universidade.Em outras palavras, por que a USP nos seus projetos e desejos de vir a ser universitários? Em primeiro plano, antes mesmo do prestígio e distinção dentro do sistema de ensino superior brasileiro, é a gratuidade das universidades públicas que aparece como fator explicativo maior. Assim, devido às condições financeiras desfavoráveis para suportar o pagamento de um curso superior, a instituição pública constitui local único no projeto de ser universitário para esses indivíduos. Essa evidência permite fazer objeções à afirmação corrente de que as

A fala de Adauto resume bem a trajetória de alguns: “... aos doze, treze anos, éramos [ele e irmãos] pequenos homens".

Sposito e Andrade (1986, p. 11), em pesquisa sobre alunos de cursos superiores noturnos, já haviam encontrado tais características: “... para este aluno do curso noturno, o trabalho é uma necessidade precoce, determinado por motivos econômicos ligados às estratégias de sobrevivência familiar.” 
camadas menos favorecidas ou "pobres" estão somente alocadas nas particulares e excluídas das públicas. É exatamente o contrário: pelo fato de ser gratuita, é lá onde o pobre, excluído, desfavorecido, popular, de baixa renda, dentre outras designações, pode ter guarida. Essa descoberta confirma o que outras pesquisas já encontraram sobre o perfil "menos privilegiado" do aluno das universidades públicas, conforme podemos apreender do estudo de Sampaio, Limongi, Torres (2000). Além disso, um outro elemento a destacar aparece bem configurado na trajetória de Mauro: trata-se da oferta de um tipo determinado de curso, caro em termos da infra-estrutura, que exige e que não oferece retorno rápido em termos de lucro, o que acaba afastando o ensino superior privado. Após concluir um curso tecnológico na Faculdade de Tecnologia de São Paulo - FATEC (instituição pública que possui cursos superiores gratuitos de graduação tecnológica), pensava em fazer Física em uma escola técnica federal; entretanto, curso de Física e no horário noturno somente seria possível na USP. A universidade pública aparece como único refúgio possível

Eu nunca prestei vestibular para escola particular. Vou estudar na USP, na Unesp ou em alguma dessas universidades públicas. (Jonas)

Eu ia falar que a minha vida é igual à do Mauro, assim... Não tinha condições financeiras também, e aqui, fosse bom ou fosse ruim, teria que ser aqui mesmo, porque era o curso que eu quero, era o único lugar que eu poderia fazer gratuitamente. (Ana)

Eu fazia cursinho e as pessoas me perguntavam: mas você não vai tentar outra faculdade? Eu falei: não, não dá. Eu até falei assim: não, eu vou passar. (Robson)

Pensei ... e agora? ... Eu era pobre, e o único lugar que eu podia fazer era na USP. Nem me preocupei se a USP era boa ou não era. (Mauro)

... quero fazer faculdade, mas não quero pagar. (Marcos)

Dependem de serviços considerados básicos para uma vida estudantil: livros e uso de computador na universidade aparecem como importantes. Ou seja, quando articulamos esse fato com a "escolha” motivada pela gratuidade acima delineada, pode-se concluir que há um reforço do papel que representa a existência da instituição pública, sem a qual muito dificilmente teriam a possibilidade de fazer um curso superior.

\section{INFORMAÇÕES, INCENTIVOS E IMAGEM}

As informações e os incentivos para que tentassem ingressar tiveram a participação de atores variados: irmãs, alunos da USP que na época ou eram professores de escola pública ou possuíam alguma ligação com a família dos pesquisados - namorados e namoradas -, além de outras situações como amigos, cursinhos comunitários e a Igreja.

Os pais dos entrevistados não possuíam aquilo que Bourdieu (1999, p. 44) julgou como um dos elementos mais importantes na composição do capital cultural, qual seja, um capital de informações sobre a dinâmica do espaço escolar. Assim, o desconhecimento da USP pelos seus pais esteve presente em todas as dezessete trajetórias. A partir dessa evidência, conclui-se que há uma diferença gritante em relação ao "grupo padrão”, o típico ingressante da USP, cujos pais possuem informação prévia sobre os tipos e posições dos cursos. Embora esse aspecto não possa ser tomado como elemento explicativo único, é evidente que constitui um dos trunfos diferenciadores para compreender o ingresso e a vivência no ambiente universitário por diferentes indivíduos

Como os meus pais são ignorantes, no sentido de não ter educação, então por eles eu não fiquei sabendo não" (Jonas).

Essa pergunta como que eu fiquei sabendo da USP, como eu vim parar aqui, eu também vivia me fazendo porque ... é difícil responder. Eu venho de uma família que a minha avó teve quinze filhos, então eu tenho uma porrada de primos e eu sou a única na faculdade, absurdo. Então, na minha família, faculdade (...) USP, pública, é algo que ninguém comentava. Para minha mãe, eu terminando lá o segundo grau [ensino médio] 'nossa, que maravilha, minha filha terminou a escola!' (Clara).

Meu pai também nem sabia o que era a USP. 'Ahhh, fiz escândalo de madrugada. Ah, tá bom, vai dormir, vai dormir!'. Caramba, eu não estou entendendo. Aí quando começaram a contar para ele 'Nossa! Você estuda na USP, a minha amiga falou que é a melhor faculdade que tem'. Ah, agora, agora que você se deu conta...” (Lúcia)

A universidade aparece como algo mágico, mítico, inatingível, sagrado, marcando, nos pla- 
nos simbólico e objetivo, fronteiras entre os que conseguem ingressar nesse espaço e os que não obtêm êxito. Fazer parte de um local prestigioso, tendo reconhecimento familiar e social, aparece como uma sensação de ter alcançado o sublime. Jonas expressa nos seguintes termos “... a família, não sei por que, mas os cunhados dão tapinha nas costas ... Você se sente bem com você mesmo ... Se sente melhor quando você passa na USP."

Esse caráter sagrado da imagem uspiana provocou vários efeitos ainda na fase anterior à entrada. Um primeiro é o juízo sobre a quase impossibilidade de acesso dos alunos oriundos da escola pública. Esses julgamentos ${ }^{9}$ são emitidos tanto por alguns professores atuantes na rede de ensino, quanto por alunos. Embora exista uma desvantagem gritante em termos de preparação para a disputa com certas escolas particulares - não todas, pois há uma heterogeneidade entre elas -, esses juízos servem como catalisadores para afastar do horizonte das camadas populares as vagas das universidades públicas. Porém, em contrapartida, despertou a luta para superar obstáculos e conseguir a vaga

Os professores sempre diziam 'ah, porque alunos de escola pública, vocês, por exemplo, não vão entrar na USP. Porque vocês têm um ensino péssimo, não sei o que...' Aí eu fiquei curiosa para saber por que eu não poderia entrar. (Ana) As duas pessoas que estavam apresentando [alunos da USP que eram monitores em programa de visita], era um homem e uma mulher. O monitor falou 'oh, aqui, vocês de escola pública, é bastante difícil entrar aqui'. Aí, a monitora já corrigiu 'É, mas não é impossível. Então ficou aquele desafio, aquela idéia de universidade, enfim, espaço público, aí, dessa forma, já comecei a trabalhar daquela série [sexta-série] até o vestibular nesse objetivo de entrar. (Antônio)

A partir da entrada na universidade, uma nova imagem começa a ser desenhada, marcando certa atenuação do caráter mágico acima delineado. Essa ponderação é desenvolvida a partir da vivência concreta dos problemas existentes. Não

${ }^{9}$ Podemos, a partir de uma reelaboração, fazer uma analogia com o estudo feito por Bourdieu e Saint-Martin sobre "as categorias do juízo professoral", levando em conta que tais julgamentos são feitos para o caso em tela antes da entrada desse grupo de indivíduos. Consulta Bourdieu (1999, p. $126-185$ ). se trata de uma ruptura total entre essas duas situações, pois a USP correspondeu, ainda que não totalmente, às expectativas, permanecendo, de certo modo, com sua "aura”; contudo, as ressalvas aparecem, esmaecendo, assim, a imagem idealizada

As pessoas pensam que só tem coisas boas... Não, tem os seus problemas. Quando entrei, eu vi os seus problemas, só que boa parte das expectativas que eu tinha em relação à universidade se confirmou (...) Problemas de acesso a laboratórios, recursos humanos, então, a universidade tem carências que, aos olhos de quem está de fora, acha que não tem. Acha que tem tudo, lá tem tudo (Jonas).

Eu achava que era tudo certinho, que tinha recursos (...) Eu faço Letras e a gente về a biblioteca têm muitos livros, tudo bem, variedade, só que tem pouco em relação à quantidade de alunos ... As salas lotadas. Eu faço Espanhol, então, às vezes, você precisa ver filmes, ouvir, etc., volta e meia os aparelhos estão quebrados. Então, é esse tipo de coisa que acaba manchando assim, né, aquela imagem que a gente tinha antes, que tudo era perfeito (Ana).

\section{ENTRANDO: ethos do esforço e esforço descomunal}

Que elementos lhes permitiram ingressar na USP? Quando relacionamos a socialização no âmbito familiar que tiveram, o percurso no nível fundamental e a trajetória ocupacional desses estudantes, alguns fatores foram fundamentais.

Ao contrário dos achados de algumas pesquisas sobre trajetórias de indivíduos de baixa renda que conseguiram chegar ao ensino superior, as quais apontam formas distintas de investimento pedagógico como centrais para explicação - compra de livros, compra de material didático extra, concessão de tempo para dedicação aos estudos, aposta total no primogênito por ter mais disciplina e desse modo conseguir melhor adaptar-se aos estudos (Lahire (1997); Sousa e Silva (2003) -, percebe-se que é um ambiente familiar calcado em um ethos do esforço e responsabilidade que produziu configurações nas quais o estudo teve condições de exercer algum tipo de atração para esses estudantes. Além disso, merecem destaque: certa estabilidade emocional, com liberdade para trilhar caminhos vários, sem imposições das carreiras a 
seguir; papel ativo de pais - sobretudo das mães em incutir o gosto pela leitura; uma postura curiosa e atenta bem desenvolvida; experiência em processos seletivos às custas de "vestibulinhos" e provas em cursinhos comunitários, além de base prévia adquirida seja em escolas técnicas estaduais que geralmente se destacam na rede pública de ensino - seja em cursos tecnológicos, o que os auxiliou no desempenho das provas, sobretudo nas disciplinas do ramo de Exatas, as mais seletivas no vestibular que fizeram. Junto a tudo isso, destaca-se um grande esforço, um esforço descomunal, marcado por sacrifícios de naturezas diversas, como conciliar trabalho e estudos, estudar nas férias, aos sábados, fazer cursinho após jornada de trabalho integral, ler no ônibus, aproveitar o pouco tempo que sobra para estudar, "não ter vida social", ${ }^{10}$ para fazer trabalhos da faculdade no fim de semana. É a confluência de tais aspectos que foi determinante para a entrada desses estudantes na Universidade de São Paulo.

\section{ESTUDANDO: dificuldades e "força interna"}

Uma série de dificuldades, tanto de ordem material quanto cultural, aparece na vida desse tipo de estudante. A maior delas é a falta de tempo para dedicação às tarefas exigidas - leituras para os cursos de ciências humanas e trabalhos e relatórios para os cursos de Ciências Contábeis e Física-, o que acaba interferindo, de modo decisivo, na consecução de um curso mais pleno. Tanto Karl Marx, nos Manuscritos Econômico-Filosóficos, em que contrastava o reino da necessidade marcado pelo trabalho alienado e o reino da liberdade, em que o tempo livre apareceria como recurso indispensável, quanto Pierre Bourdieu, em suas reflexões sobre os liames entre capital econômico e capital cultural, possibilitam-nos elementos essenciais para a compreensão da fruição dos estudantes dos segmentos desprivilegiados da população, marcados pela obrigação de ter de trabalhar para sobreviver.

\footnotetext{
${ }^{10}$ Expressão de Ana.
}

... é por intermédio do tempo necessário à aquisição que se estabelece a ligação entre capital econômico e o capital cultural (...) o tempo durante o qual determinado indivíduo pode prolongar o seu empreendimento de aquisição depende do tempo livre que sua família pode lhe assegurar, ou seja, do tempo liberado da necessidade econômica, que é a condição de acumulação inicial (Bourdieu, 1999, p. 76).

Como se resolve ou, ao menos, tenta se resolver tal ausência de tempo? "Cria-se" algum tempo em horários destinados a outras rotinas diárias - hora do almoço, período após expediente, dentre outros. A conseqüência mais imediata é uma nova postura frente às atividades universitárias. É exigido do aluno um novo e diferente grau de organização, para que consiga executar os deveres solicitados a contento. Com efeito, o controle do tempo configura-se como elemento crucial, sob pena de ser "engolido" pela grande quantidade de tarefas, conforme expressa Mauro

Você tem que arrumar algum tempo - na hora do almoço, das 24:00 às 6:00 hs (...) você tem que ter um nível de organização que, às vezes, você não está acostumado a ter: esse tempo eu vou usar para estudar, esse tempo eu vou usar para a família, esse tempo eu vou para o serviço. Eu vivo numa corda bamba com o tempo.

A distância da moradia de boa parte dos pesquisados - em bairros afastados e alguns em municípios da Grande São Paulo - também se configura como uma das grandes barreiras enfrentadas pelos estudantes. Alguns, como Lúcia e Clara, tiveram de mudar e passar a pagar aluguel para residirem nas proximidades da USP, sob pena de terem de desistir do curso.

Se as dificuldades materiais remetem a transporte, alimentação, dinheiro para xerox, aquisição de livros, dentre outras, as dificuldades simbólicas ou culturais ${ }^{11}$ são mais sutis, pois ligadas à socialização no ambiente familiar e à trajetória peculiar do indivíduo, e lidam diretamente com a inserção acadêmica em termos de novas tarefas a serem feitas: textos escritos em línguas estrangeiras, seminários, trabalhos científicos e leitura de textos

${ }^{11}$ Essa distinção é para efeito analítico, pois, na realidade, há combinações complexas entre as mesmas. 
acadêmicos, para o que se exige a compreensão de questões teórico-metodológicas, premissas do autor, idéias centrais de um texto, teorias divergentes, dentre outros pontos correlatos.

Tem professor que fala assim: 'tenho um livrinho que é bibliografia básica, só que tem um probleminha, é em francês'. Então, é uma dificuldade muito grande, porque espanhol nós lemos muito, dá pra levar, mas francês, inglês, eu tenho uma dificuldade enorme (Jonas).

Literatura portuguesa usa muito francês. Agora a gente está no Simbolismo, tem muito Mallarmé [poeta francês], tudo em francês. Então, o professor estava dizendo 'gente, vocês já deveriam saber francês', e a gente achou um absurdo, porque eles acham que, pelo fato de a gente estar na USP, supõe que você sabe inglês, francês, espanhol e tudo (Ana).

... Marcos: o problema, às vezes, é que você tem dificuldades para acompanhar algumas matérias mais técnicas na Geografia. Wilson: Destrincha mais esses problemas para mim. Marcos: São cálculos. Nós temos algumas dificuldades com cálculos, algumas dificuldades com relações químicas. Existe uma deficiência, porque o ensino médio é muito deficiente. Eu entrei aqui com essa deficiência e eu passei no vestibular da Fuvest, vestibular normal que nem todo mundo (...) Sensoriamento Remoto, a professora fala que não vai levar a gente pro computador, porque tem aluno que nẫo sabe mexer no computador.

Eu tive, muitas vezes, que pegar aquele livro do ensino médio, estudar novamente pra entender alguma proposta, alguns exercícios de Cartografia, daquilo que, aparentemente, é básico no curso. Eu tive que voltar e analisar, porque eu não estava acompanhando, faltava, então, um pouco de base (Antônio).

A leitura não é aquela que você faz corrida; são teorias e, às vezes, você tem dificuldade para entender em português, ainda mais uma língua que você não conhece (...) Os valores embutidos numa palavra você desconhece (Clara).

Dos dezessete estudantes, apenas dois desistiram: Isabela abandonou o curso de ciências contábeis e foi em busca de seu desejo, que é fazer medicina. Robson, após obter uma promoção no emprego, optou por abandonar o curso de história. Dada a situação desgastante na qual estão inseridos, onde há uma frágil conciliação entre jornada de trabalho e alto nível de exigência em uma universidade de prestígio, por que não desistem dos cursos? O que os leva a seguir em frente? O esforço para driblar as dificuldades que surgem transforma-se no combustível capaz de mantê-los na direção de completar o curso, às expensas de muitos sacrifícios.
Wilson: será que vale a pena continuar, apesar do balanço que vocês fizeram dos pontos negativos e positivos do fato de estudar na USP? (...)

Carlos: realmente, tem horas que você treme, mas você tem que buscar uma força interna para continuar. Éééé [Concordância geral]. Tem hora que bate aquele desânimo 'nossa, não agüento mais, não tenho vida social'. Mas, a gente sabe que é importante continuar (Carlos).

\section{FRUIÇÃO: o tempo entre a elite e o trabalhador}

A falta de tempo, devido à necessidade de trabalhar, produz uma clivagem entre o estudante que tem tempo, posto que não trabalha, tido como um indivíduo que pode aproveitar a USP mais plenamente e, por isso, fazer um curso melhor, aprender mais. ${ }^{12}$ Aqui, temos uma fronteira objetiva bem delimitada entre os alunos da USP nos termos de Lamont e Molnar (2002), a qual acarreta diferenças incontornáveis no plano simbólico. Um episódio ocorrido no primeiro ano, descrito pela Ana, marca a tensão entre o tempo livre para realização de um bom curso, sugerido por uma docente, e a situação real dos alunos, na qual reina o tempo escasso, devido ao trabalho integral diário: “... a professora falou: 'gente, se vocês querem fazer um curso bom de letras, vocês não podem trabalhar'. A sala toda quase vaiou a professora, porque quase todo mundo, à noite, trabalha”.

Adauto emite juízo análogo ao da Ana, quando diz que a falta de base em línguas - outra chave que permite distinguir a "elite" do estudante desprivilegiado - acaba interferindo em um melhor desenvolvimento do curso.

O professor mostrou isso para a gente, na classe. Ele falou: 'olha, isso aqui em francês não tem nada a ver com o que é traduzido, a idéia que o cara tá querendo passar aqui é totalmente outra'. Então, pra quem sabe o francês, vai se dar melhor, vai fazer diferença (...) Então, por isso que o professor diz: 'Ah, tá bom, não precisa se preocupar porque a gente dá em português', mas ele tá dando ali o último recurso (Adauto). 12 “... aquelas pessoas que não trabalham, acabam tendo
mais vantagens, acabam sabendo mais, porque pode se dedicar" (Ana). 
Carolina aponta, de modo claro, a diferenciação interna entre os estudantes uspianos, independentemente dos cursos que freqüentam, rebatendo fortemente no uso diferente que os mesmos fazem desse espaço:

A faculdade, ela é feita pra quem não precisa trabalhar. A faculdade te oferece muita coisa (...) Quando a faculdade oferece esse tipo de coisa e você não pode participar, te deixa muito chateada (...) Essa menina, que é estudante de História no vespertino e também assiste aulas à noite, por exemplo, ela já fez Iniciação Científica, estava num grupo de um professor. Tem um outro, que também faz parte do grupo dela, um garoto magrinho alto, tá no grupo desse professor, fazendo pesquisa. São pessoas privilegiadas, elas têm uma possibilidade, elas estudam no vespertino, elas têm a noite inteira para poder desenvolver os grupos, as leituras, pra tudo, porque são pessoas que não precisam trabalhar - não estou falando que as coisas são fáceis por esse motivo, não sei da vida particular de cada um, mas, a partir do momento que você não tem esse compromisso de ter que trabalhar para se manter... (Carolina)

Há um subgrupo de alunos formado por Adauto, Gilberto e Marcos, que têm a possibilidade de uma maior fruição da universidade quando contrapostos aos que trabalham em tempo integral e não moram na USP. Assim, tempo e distância aparecem como elementos importantes para apreender a dinâmica do uso do espaço universitário pelos pesquisados. Afastam-se da maior parte por morarem na USP. Por outro lado, aproximam-se dos outros, pois, embora trabalhem meio período ou possuam folgas no trabalho, reclamam por não poderem ir às atividades existentes devido ao trabalho. Gilberto expressa claramente:

Eu tenho o privilégio de morar aqui, eu moro no CRUSP (Conjunto Residencial dos Alunos da USP) né? Então, aos poucos, eu fui conhecendo tudo o que a USP oferecia (...) Eu uso regularmente. Tem tudo o que você queira fazer (...) Tenho grandes críticas, porque eles só fazem nos horários que a gente não pode freqüentar. Os simpósios ocorrem durante o dia, horário em que eu trabalho.

Embora o tempo seja variável central, não é suficiente como explicação, pois importaria saber como melhor empregá-lo. Em conseqüência, a formação anterior do indivíduo, seu background, nos termos de Bourdieu, um habitus, aparece como elemento central para equacionar de forma mais equilibrada o que aqui chamo de fruição.

\section{PAPEL DA UNIVERSIDADE}

Se as desigualdades educacionais são produzidas, substancialmente, em outros âmbitos, até que ponto a universidade pode intervir? Qual o seu limite? Parece que a universidade ainda está distante de entender a parte que lhe cabe na produção e reprodução das desigualdades. Conforme apontou Villas Bôas

...nos depoimentos colhidos, é recorrente a evoca-
ção de uma entidade impessoal, a sociedade ou o
sistema, cujo funcionamento precário distribui
mal os bens de renda, educação, justiça, etc., para
justificar as desigualdades entre os alunos. Nẫo se
considera o fato de que a universidade também
seleciona e partilha (...) A resistência dos docen-
tes não é a de encarar as desigualdades sociais,
mas, sim, de percebê-las dentro da universidade
(2001, p. 111).

A indagação acima leva a discussão para uma análise sobre um olhar mais interessado dos órgãos universitários em relação a alguns pontos. Primeiramente, aquilo que poderia ser denominado a recepção ao aluno ingressante, no sentido de uma comunicação e fornecimento de informações sobre os serviços existentes, sobretudo para aqueles que poderiam ser de elevado auxílio, para estudantes socialmente menos favorecidos. Ponderando que a USP possui diversos serviços e programas, diferenças entre suas unidades, além do interesse do próprio estudante em procurar inteirar-se a respeito do que existe para ajudá-lo, as evidências empíricas apontam um problema de integração e maior divulgação institucional. Isso influencia fortemente a possibilidade de fruição dos estudantes desfavorecidos, que têm, assim, uma oportunidade subtraída

Lúcia: No meu primeiro dia de aula, vim lá de Itaquera [bairro da zona leste paulistana, a USP fica na zona oeste]. Não é possível, gente, não mostram nem uma sala de aula pra gente, é complicado.

Marcos: O que a USP te oferece quando você está aqui? 
Lúcia: É...

Marcos: Neste sentido, as bibliotecas, como se usam?.

Lúcia: É muita informação para uma pessoa se virar sozinha...

Marcos: É muita coisa pra você que está entrando.

Lúcia: A verdade é essa: eles fazem de tudo pra você se virar sozinho.

Clara: Acho que a comunicação é muito grave aqui, por exemplo, você entra e ... como isso se dá, como acontece, de boca a boca. 'Ah, que é isso, amigo? Isso é pra todo mundo? Como que eu faço?' Você não sabe.

Gilberto: A estrutura é muito grande, você nunca tem acesso a tudo, você nunca sabe de nada. Eu estou no terceiro ano e tenho certeza de que tem muitas coisas que eu não conheço na USP.

Mário: É, eu também.

Gilberto: E vou sair daqui sem conhecer.

Clara: Sem usar, sem saber que existe...

Ao examinar das evidências, percebe-se que um olhar mais atento para essas ocorrências seria muito salutar, pois, sem ele, há um reforço às desigualdades sociais, ao não reconhecer as especificidades de determinado segmento dentro da prestigiosa USP. Em outros termos, não se reconhece a luta de muitos em busca da consecução de um "curso decente", apesar de todas as adversidades, como expressa Clara:

Acho que poderia se discutir... Se preocupar um pouco mais, que a realidade de nossa cidade, de nosso estado, de nosso país, ainda é outra, e muita gente aqui tem que driblar um monte de situações para conseguir levar o curso; deveriam pensar um pouco mais nessas pessoas.

\section{CONCLUSÃO}

Embora os dezessete estudantes se aproximem em muitos pontos, existem também, entre eles, muitas diferenciações e singularidades que não nos permitem considerá-los como um bloco homogêneo em quaisquer dos questionamentos abordados. É preciso ressaltar essa ocorrência, a qual aponta para a complexidade presente no estudo desse tipo de aluno. Assim, há clivagens bem demarcadas, desde o momento em que passaram a obter informações sobre a Universidade de São Paulo.
$\mathrm{Na}$ fase anterior ao ingresso foi decisivo o papel dos pais e irmãos, amigos, namorado (a) e professores - alguns dos quais alunos da USP que serviram tanto como incentivadores e modelos a serem seguidos, quanto passando orientações. Apesar das múltiplas configurações, há o traço comum que permite ligá-los e diferenciá-los de outros segmentos sociais: a falta de um capital familiar de informações sobre a universidade.

Elementos como um ambiente familiar com certa estabilidade emocional, um olhar atento de pais que valorizavam a educação como ferramenta para mobilidade social, o papel de mães em incutir o hábito de leitura desde a mais tenra idade, uma trajetória relativamente segura durante o ensino fundamental e uma confluência de fatores na fase pré-vestibular - experiência em processos seletivos, base prévia obtida em cursos técnicos e tecnológicos, autodidatismo - permitiram-lhes conseguir a vaga. Subjacente a esses elementos, que são variáveis de acordo com as trajetórias em questão, há algo que os une desde a socialização primária até a vivência na universidade: um esforço incomum para enfrentar duros obstáculos que se põem à vista. Até mesmo quando são emitidos julgamentos negativos sobre suas chances na disputa pela vaga - o que geralmente afasta muitos indivíduos com condições sociais desfavoráveis -, esse aspecto concorre para instigar-lhes a provar que são capazes, acabando por servir como trunfo para o sucesso no vestibular.

Se eles não possuem vantagens sociais, há, contudo, uma marca que serve como fulcro explicativo para esse grupo. Nos três eixos do estudo, encontramos esse molde: seja na socialização primária, tendo como referência pais e irmãos, nos seus próprios trajetos ocupacionais, na trajetória de ingresso e, por fim, nas suas vivências na universidade, onde convivem com duras dificuldades para levar o curso adiante. Em todos esses momentos estão imbricados valores como determinação, independência, responsabilidade, maturidade, postura pró-ativa, luta, bem amalgamados, pois regularmente acionados. E é justamente esse traço que os capacita para o trabalho autônomo, o 
"se virar", marca preponderante das exigências cotidianas no espaço universitário em questão. Assim, é como se houvesse, para esses estudantes, uma correspondência entre um esforço e um espaço que o requer. Nos termos de Bourdieu (2002, p. 167), uma prática.

Porém há limites em suas experiências, bem nítidos, quando se problematiza o processo de "escolha" dos cursos: estão afastados das carreiras mais disputadas - o que gera desejos interditados e compensações nem sempre felizes - e, ressaltase, percorreram um longo e custoso caminho para chegar aos cursos que fazem.

Antes do ingresso, cultivavam uma visão idealizada desse espaço. A vivência como aluno propiciou uma visão crítica, expressa nos problemas práticos enfrentados em suas respectivas unidades de ensino e nas restrições ligadas aos limites objetivos impostos pela condição social, dentre as quais se destaca a necessidade de trabalhar, ocasionando a escassez de tempo para dedicação aos estudos. Além disso, um convívio com dificuldades econômicas e simbólicas veio à tona: no nível material, desponta a distância do campus, a falta do aporte financeiro para compra e xerox de livros, a utilização de computadores somente na universidade e a consideração do restaurante universitário como espaço importante. Na dimensão propriamente cultural, aparecem dificuldades como a falta de domínio de línguas estrangeiras para leitura, como diferencial do ponto de vista do aproveitamento do curso, e, também, obstáculos ligados a uma base conceitual requerida para dar conta das leituras que envolvem o contato com teorias científicas. A universidade é um novo local de estudos que requer a aprendizagem - muitas vezes feita de modo penoso - de novos tipos de tarefas escolares, na maioria das vezes desconhecidas por esses estudantes, como a apresentação de seminários, relatórios e trabalhos, as quais, quando relacionadas com o alto nível de exigência, pedem uma habilidade para administrar um tempo que já é exíguo, devido à necessidade inadiável do trabalho para sobrevivência.

Nesse bojo se insere a fruição, a qual enseja uma diferenciação no interior da USP, mediada por dois aspectos cruciais: tempo disponível e distância da universidade. Uma pergunta permanece: até que ponto esses trabalhadores-estudantes "passam" pela USP, apropriando-se apenas de uma parte pequena do amplo "currículo aberto" que ela possui? Um "currículo" que varia desde o uso em toda plenitude dos livros e periódicos de uma biblioteca, até o contato mais estreito com professores. Não há elementos suficientes para responder essa questão a contento, porém, temos indicativos que podem ser úteis: dispor de mais tempo, a partir das evidências coligidas, não é suficiente como explicação. Outros momentos ainda precisam ser mais considerados, como a trajetória específica do indivíduo, sua formação e predisposição para valorizar determinados aspectos disponíveis em uma universidade pública.

Por fim, se a universidade não pode ser considerada uma instância que, por si só, resolverá diferenças sociais, as evidências apontam que se faz necessário, da mesma forma, repudiar a visão que a quer neutra, pois, quando ela não olha de modo mais interessado para as desigualdades que estão sobre seu terreno, acaba intensificando as disparidades previamente existentes. Em decorrência, após a investigação realizada, cada vez mais, pode-se concluir que a permanência no ensino superior deve ser entendida como uma interação entre condicionantes estruturais da sociedade e as ações conjunturais que estão ao alcance, dentro de seus limites, das universidades. Os resultados encontrados apontam que os órgãos universitários poderiam ter uma postura mais ativa. Sem isso, talvez, o debate atual sobre uma maior inclusão social no ensino superior pode estar encobrindo uma de suas dimensões mais centrais, qual seja, que o conhecimento a todos oferecido é mais satisfatoriamente apropriado apenas por alguns, como bem expressou Adauto "A facilidade é essa: você ter as coisas aqui perto. Por outro lado, nem tudo que está aqui perto está a seu alcance".

(Recebido para publicação em novembro de 2006) (Aceito em abril de 2007) 


\section{REFERÊNCIAS}

BONNET, M.; CLERC, N. Des "héritiers" aux "nouveaux" étudiants: 35 ans de recherches. Revue Française de Pedagogie, [S.l.], n. 136, p. 9-19, juil./août/sept. 2001.

BOURDIEU, P. La distincion: criterios y bases sociales del guesto. Madrid: Taurus, 1988. [1979]

Escritos da educação - Pierre Bourdieu. São Paulo: Ática, 1999. Organização de Maria Alice Nogueira e Afrânio Mendes Catani.

Esboço de uma teoria da prática: precedidos de três estudos de etnologia. Cabila, PT: Celta Editora, 2002

; PASSERON, J. C. Les héritiers: les étudiants et la culture. Paris: Edit. Minuit, 1964.

BOWL, Marion. Experiencing the barries: non-traditiona students entering higher education. Research Papers in Education, [S.1.], v. 16, n. 2, p. 141-160, 2001.

ERLICH, Valérie. Les nouveaux étudiants: un groupe social en mutation. Paris: Armand Colin, 1998.

. The 'new' students and the studies and social life of French University Students in a context of mas education. European Journal of Education, [S.1.], v. 39 n. 4, p. 485-495, 2004

FERNANDES, Florestan. Fundamentos empíricos da explicação sociológica. São Paulo: Companhia Editora Nacional, 1959.

FORRACHI, M. M.. O estudante e a transformação da sociedade brasileira. São Paulo: Companhia Editora Nacional, 1965.

A análise sociológica da educação. In: . A participação social dos excluídos. São Paulo: $\overline{\text { Hucitec }}$ 1982, p. 64-82

O estudante universitário: resultados iniciais de uma investigacão sociológica. In: A participaçã social dos excluídos. São Paulo: Hucitec, 1982. p. 155-158.

GOMES, Jerusa V. Jovens urbanos pobres: anotações sobre escolaridade e emprego. Revista Brasileira de Educação, [S.l.], n. 5-6, p. 53-62, 1997.
HIRANO, Sedi et al. A universidade e a identidade da condição estudantil: um estudo sobre a situação sócioeconômica, níveis de saúde e modo de vida dos estudantes da USP. Temas IMESC, Soc. Dir. Saúde, São Paulo, v. 4, n.1, p. 83-108, 1987.

LAHIRE, Bernard. Sucesso escolar nos meios populares: as razões do improvável. São Paulo: Ática, 1997.

LAMONT, M.; MOLNÁR, V. The study of boundaries in the social sciences. Annual Review Sociology, [S.l.], v. 28, p. 167-95, 2002 .

PORTES, E. A. O trabalho escolar das famílias populares In: NOGUEIRA, M. A. et al. Família \& Escola: trajetórias de escolarização em camadas médias e populares. Petropólis: Vozes, 2000. p. 61-80.

ROSS, Alistair et al. Higher education and social class: issues of inclusion and exclusion. London: Routledge, 2003.

SAMPAIO, H. (Coord.); LIMONGI, F; TORRES, H. Eqüidade e heterogeneidade no ensino superior brasileiro. São Paulo: NUPES/USP, 2000.

SOUSA E SILVA, J. Por que uns e não outros?: caminhada de jovens pobres para a universidade. Rio de Janeiro: Editora Sette Letras, 2003.

SPOSITO, M. P.; ANDRADE, C. L. de. O aluno do curso superior noturno: um estudo de caso. Cadernos de Pesquisa, São Paulo, v. 57, p. 3-19, maio 1986

TERENZINI, P. T. et al. Swimming against the tide: the poor in American Higher Education. College Board Research Report n. 1. New York: College Entrance Examination Board, 2001.

VIANA, Maria José Braga. Longevidade escolar em famílias de camadas populares: algumas condições de possibilidade. In: NOGUEIRA, M. A et al. Família \& Escola: trajetórias de escolarização em camadas médias e populares. Petropólis: Vozes, 2001. p. 45-60.

VILLAS BÔAS, Glaucia. Seleção e partilha: excelência e desigualdades sociais na universidade. Teoria \& Sociedade, Belo Horizonte, v. 7, p. 95-115, jun. 2001

ZAGO, N. Do acesso à permanência no ensino superior: percursos de estudantes universitários de camadas populares. In: REUNIÃO ANUAL DA ANPED,28, Caxambu, MG, p. 1-16, out. 2005. 


\section{ESTUDANTES COM DESVANTAGENS ECONOMICAS E EDUCACIONAIS}

Wilson Mesquita de Almeida

O texto discute os principais resultados de uma investigação que teve como objetivo apreender a utilização dos recursos e espaços da Universidade de São Paulo por um grupo de estudantes com desvantagens econômicas e educacionais. A partir de uma revisão crítica da bibliografia nacional e estrangeira sobre a trajetória de estudantes provindos das camadas populares que chegam ao ensino superior e da interpretação dos dados empíricos coligidos, refletese sobre o que esses alunos, efetivamente, aproveitam da estrutura propiciada pela universidade. Os alvos da investigação voltam-se para verificar como ocorreu o processo de socialização no ambiente familiar; a reconstrução da trajetória de ingresso e o trânsito no ambiente universitário mediante a apreensão do cotidiano, da adaptação à linguagem acadêmica, da realização dos afazeres, além do contato com indivíduos de origem similar bem como de outros estratos sociais. A pesquisa utilizou a metodologia qualitativa, operacionalizada em duas fases: grupos focais e entrevistas semiestruturadas com o objetivo de refinar as principais categorias surgidas. Espera-se contribuir na reflexão sobre os debates atuais em torno da inclusão social no ensino superior ao integrar à análise do acesso à universidade, uma discussão sobre a efetiva permanência, onde o foco passa a ser um estudo mais pormenorizado das diferenças na qualidade da educação recebida pelos diversos segmentos sociais presentes na universidade pública.

PALAVRAS-CHAVE: desigualdades educacionais, ensino superior, elites sociais e econômicas, universidade pública, inclusão social.

\section{STUDENTS WITH ECONOMICAL AND DUCATIONAL DISADVANTAGESAND FRUITION OF THE UNIVERSITY}

\section{Wilson Mesquita de Almeida}

This text discusses the main results of an investigation that had as its ef était d'appréhender l'utilisation des resources and spaces of the University ressources et des espaces del'Université of São Paulo by a group of students with de São Paulo faite par un groupe economical and educational d'étudiants défavorisés sur le plan disadvantages. Starting from a critical économique et éducationnel. Il s'agit revision of the national and foreign d'une réflexion réalisée à partir d'une bibliography on the path of students révision critique de la bibliographie stemming from society's poorer layers nationale et étrangère sur la trajectoire that arrive at higher education and of the des étudiants issus de couches populaires interpretation of the empiric data et qui entrent dans l'enseignement gathered, a reflection is made about what supérieur ainsi que d'une interprétation hose students effectively take of the des données empiriques y relatives. On structure propitiated by the university. cherche également à savoir en quoi ces The investigation aims to verify how the élèves profitent effectivement de la socialization process happened in the structure offerte par l'université. Le but family atmosphere; as well as how de cette recherche est de vérifier happened the reconstruction of the comment le processus de socialisation a entrance path and the traffic in the eu lieu dans le milieu familial; la academical atmosphere through the reconstruction de la trajectoire d'insertion understanding of daily life, the adaptation et de passage dans le milieu universitaire to the academic language, the moyennantl'appréhension duquotidien, accomplishment of academic tasks, l'adaptation au langage académique, la besides the contact with individuals of réalisation des tâches, sans compter le similar origin as well as from other social contact avec des personnes d'origine strata. The research used the qualitative similaire ou d'autres couches sociales. methodology through two phases: focal Pour cette recherche on a utilisé une groups and semi-structured interviews méthodologiequalitative réalisée en deux with the objective of refining the main étapes: des groupes focalisés et des categories to appear. This paper hopes to entretiens semi-structurés ayant pour contribute in the reflection on the current objectifdepréciser les principalescatégories debates around the social inclusion in qui ont surgi. On espère ainsi apporter hehigher education through integrating une contribution à la réflexion sur les discussion on the effective permanence débats actuels concernant l'inclusion to the analysis of the access to the sociale dansl'enseignement supérieur, en university, where the focus becomes a y intégrant l'analyse de l'accès à more detailed study of the differences in l'université, une discussion sur la the quality of the education received by permanence effectiveà partir d'une étude the several present social segments in détaillée de la différence de qualité de the public university.

KEYwORDS: educacional unequalities, higher education, social and economic elites, public university, social inclusion. l'éducation reçue par les diverses couches sociales présentes au sein de l'université publique.

Mots-CLÉs: inégalités au niveau de l'éducation, enseignement supérieur, publique, inclusion sociale. élites sociales et économiques, université

Wilson Mesquita de Almeida - Mestre em Sociologia pela Universidade de São Paulo com bolsa da FAPESP, 2006. Atualmente é professor do Centro Universitário Nove de Julho - UNINOVE - S. Paulo. Ganhou Concurso Nacional de Monografia - Educação, Diversidade e Cidadania, Secretaria de Educação Continuada, Alfabetização e Diversidade SECAD/MEC e ANPED, 2006. Principais linhas de pesquisa: acesso e permanência de segmentos populares no ensino superior; educação superior brasileira; desigualdades educacionais. 